\title{
Pulgas, leones y otros monstruos de la imprenta ilustrada: de la Poética de Horacio al Tigre de William Blake
}

\author{
Ana Elena GonZÁLEZ TREVIÑo \\ Universidad Nacional Autónoma de México
}

La imprenta en el siglo XVIII representa, en libros de zoología, imágenes de animales acompañadas de textos que buscan ser científicos pero que siguen impregnados del discurso prerracionalista; al hacerlo, originan una nueva versión de los monstruos que poblaron el discurso anterior desde la Antigüedad y la Edad Media hasta la modernidad temprana. Paralelamente, la estética literaria del periodo ensalza la moderación y la mesura y prescribe la evitación del exceso y la discordancia; la reacción romántica a finales del siglo procura rescatar el asombro perdido ante los animales.

PALABRAS CLAVE: representación de animales, imprenta en la Ilustración, estética dieciochesca, historia de la ciencia.

Eighteenth-century printed zoology books represent images of animals anchored by texts which purport to be scientific but which continue to be impregnated by pre-rationalist discourse; in doing this, they originate a new version of the monsters which populated former discourse from classical Antiquity and the Middle Ages, and up to the early modern period. Analogously, the period's literary aesthetics exalts moderation and containment, while prescribing the avoidance of excess and discord; the romantic reaction towards the end of the century attempts to reinstate the sense of wonder regarding animals.

KEY WORDS: animal representation, the printing press in the Illustration, eighteenth-century aesthetics, history of science.

La representación de animales en libros de zoología del siglo XVIII, tanto en la imagen como en el texto que la acompaña, está impregnada de imágenes literarias que permiten la supervivencia — poética— de la idea del monstruo, aun ya impuesto el paradigma científico de la Ilustración. La monstruosidad se entiende como una unión hiperbólica de elementos discordantes en un todo que por contraste contextual se describe como anormal. ${ }^{1}$ Dichos elementos suelen definirse en términos de exceso o desbordamiento ya sea en magnitud o en peligrosidad. Tanto en estética como en biología, en literatura

\footnotetext{
${ }^{1}$ La palabra monstruo viene del latín, mostrum, que es una advertencia, señal divina o portento; también se usa para describir una figura anormal. En el siglo XIV se extiende a animales imaginarios compuestos de partes diversas de varios animales, como el grifo o el centauro. No es sino hasta el siglo XV que se emplea
} 
como en medicina, un monstruo produce un evento voyeurístico que desata un efecto emocional de risa o miedo, una mezcla de asombro y repugnancia, que subraya y confirma su calidad de monstruoso, así como la "normalidad" del espectador. El concepto del monstruo funciona por oposición a una concepción estable del mundo creado, y guarda lazos estrechos con los relatos primigenios que buscan explicar la diversidad de las criaturas como un muestrario ordenado de la creatividad divina o natural. En un contexto judeo-cristiano, se piensa en primera instancia en las criaturas del reino animal que, siguiendo el ejemplo de Adán en el libro del Génesis, el ser humano describe y clasifica según nomenclaturas y jerarquías inventadas por sí mismo. De acuerdo con éstas, cada especie tiene características que le son propias de manera exclusiva; la pertenencia a una nomenclatura dada es lo que garantiza la estabilidad de su identidad. En cambio, cualquier variante, sobre todo si se trata de la exageración de algún rasgo que acentúe su ferocidad, se considera una transgresión y llevará el mote de monstruoso, en una mezcla de desprecio y azoro. El monstruo, dice Foucault, es lo que "hace aparecer la diferencia" (Foucault: 157).

En los albores de la historia, el monstruo rondaba en el oscuro espacio del misterio. En tanto que ocupaba el centro incognoscible del relato mítico, estaba imbuido de un poder simbólico que refrendaba su vigencia a lo largo de las épocas y lo volvía inmortal. Los animales fantásticos o imaginarios se describen como monstruosos cuando tienen un aspecto maléfico o amenazante, pero en todo momento cumplen el propósito de evocar poderes sobrenaturales que en algunas ocasiones se pueden enjaezar para ayudar a la humanidad a sortear obstáculos que de otro modo serían inexpugnables, aunque en otras son el enemigo a vencer. Funcionan casi como una entidad abstracta que representa la ferocidad descomunal de las fuerzas de la naturaleza, de la adversidad, del mal o de la historia misma. Son el desafío, la motivación que permite que un hombre común y corriente se convierta en héroe al derrotarlo. El arcángel Miguel, san Jorge o Teseo, por mencionar sólo tres de los ejemplos más conocidos, se representan siempre como los subyugadores de monstruos o del demonio mismo, en una iconografía de la masculinidad triunfante sobre la bestia que por mucho repetirse se percibe como natural.

Con la secularización progresiva de las sociedades y los avances de la ciencia y la tecnología, estos monstruos poco a poco se van empequeñeciendo, pues se confunde la dimensión simbólica con la dimensión material de las cosas. El espacio a explorar es el mundo material y es en ese escenario donde el hombre ilustrado representará el espectáculo de su dominio. El cambio de paradigma, sin embargo, no se da de la noche a la mañana, sino de manera gradual, y durante mucho tiempo convive la antigua concepción de los monstruos con el nuevo modo de describir a las criaturas. Por ejemplo, la literatura de viajes cumple una función doble en este sentido: por un lado contribuye a propagar la idea de que los monstruos sí existen al presentar testimonios personales de supuestos atisbos o encuentros, y por el otro, lentamente rompe con 
estas creencias a través de testimonios opuestos. Se presentan ante el público ambas versiones de manera simultánea con el propósito implícito de que cada quien elija la que considere mejor; sin embargo, el magnetismo de lo monstruoso y los misterios de la naturaleza se siguen combinando en los libros para despertar asombro en los lectores.

Conforme se va implantando el paradigma racionalista, la tendencia irreversible es comprobar empíricamente que aquellos seres, al no tener existencia física, no tienen existencia. Punto. El racionalismo busca expulsar la concepción misma del monstruo sobrenatural y reducirlo a lo natural; reconocerlo, nombrarlo, anatomizarlo, son acciones que lo vuelven pequeño y susceptible de ser representado científicamente, ya despojado de su aura atemorizante. En la Ilustración, el monstruo es un Leviatán que sale de lo profundo del abismo oceánico y que va perdiendo poco a poco sus rasgos terribles para convertirse en una pobre anomalía del mundo natural, una bestia más en el zoológico de la soberbia humana, reductible y constreñido a una nomenclatura.

Todo discurso, incluso el científico, está inmerso en procesos históricos y culturales, determinados por la ideología imperante. Los sesgos ideológicos suelen pasar inadvertidos para quienes los viven de manera contemporánea, pero se vuelven evidentes con el paso del tiempo. No obstante, en los momentos históricos en los que se suscitan los cambios de paradigma, se delatan los valores imperantes de una sociedad y ya no parecen tan universales como lo parecían en un primer momento. La transición de un tipo de representación a otra — por ejemplo, de la mítica a la racionalista — brinda una oportunidad única de observar de cerca las propensiones ideológicas, los prejuicios y suposiciones que en todo momento conforman cualquier discurso dominante. Así, la representación "científica" del mundo animal así como de la dimensión monstruosa, involucra sin querer cuestiones ideológicas muy polémicas tales como la pureza racial, el hibridismo, el exotismo y la desigualdad de las naciones y los géneros.

Una transición de este tipo ocurre en los siglos XVII y XVIII, cuando los relatos de viajes y los libros de historia natural reciben la propulsión de los adelantos de la tecnología tales como el microscopio o la imprenta para las masas, para crear un nuevo tipo de conocimiento libresco, moderno y que buscaba ser más fidedigno que ninguna representación del pasado. El catálogo de lo representable dentro del medio impreso, es decir, de lo que se podía incluir en un libro, se multiplica; esto, aunado a la reproducción a gran escala, revoluciona el conocimiento al volverlo accesible a un mayor número de personas, y a fuerza de repetición, refrenda su valor de verdad. Gracias a los libros, el espacio para el encuentro con lo natural y lo monstruoso también se modifica: puede darse desde la intimidad del hogar, la cafetería o la taberna, cuando la familia entera o los miembros de una tertulia se reúnen, leen, ven y reaccionan en conjunto corroborando las creencias de uno y otro.

Paradójicamente, las categorías científica y estética se rigen por principios análogos, y a menudo resulta imposible deslindarlas. La preceptiva literaria buscará valores científicos, como la objetividad, y los textos científicos no podrán evitar las valoraciones estéticas al comentar, por ejemplo, acerca de la belleza o fealdad de tal o cual animal. Mi propósito es explorar el tema de la monstruosidad, inicialmente, desde el 
punto de vista estético-literario de la Ilustración, para luego presentar una selección de representaciones del mundo natural en libros del siglo XVIII que revelan la propensión ideológica del periodo. Me interesa sobre todo subrayar la cualidad libresca de estos monstruos, ya sea a través de los autores de la Antigüedad clásica, o a través de las rectificaciones "científicas" de textos vernáculos. En primera instancia presento un texto de preceptiva literaria para luego contrastarlo con las representaciones de animales en distintos libros del siglo XVIII. El texto que acompaña la imagen circunscribe y reduce la lectura de ésta, pero, en tanto que depende de la palabra escrita, utiliza recursos literarios y retóricos que revelan prejuicios culturales que modelan la experiencia "científica". ${ }^{2}$

Uno de los textos literarios que cimientan la actitud neoclásica hacia los monstruos es el Arte poética de Horacio, que abre con una superposición de imágenes disímbolas reunidas en una sola criatura monstruosa: un rostro humano con cuello de caballo, miembros de otros animales y todo adornado de plumas; una hermosa mujer con cuerpo de pez "enorme y feo", según la traducción de Tomás de Iriarte de 1777. Estas combinaciones de partes de distintos cuerpos en un contexto prerromántico y preFrankenstein, acusan, más que una transgresión trascendente o espiritual, una simple falta de decoro artístico que debe evitarse, pues cada rasgo debe ocupar el lugar que le corresponde y no otro, es decir, el lugar que le asignan las leyes "naturales". La misma falta de armonía reina en las composiciones literarias hechizas que parecen "sueños de enfermos delirantes" (Horacio, 1777). ${ }^{3}$ Del mismo modo, su amigo y luego acérrimo rival, Félix María de Samaniego, plasmó estas ideas en su versión más libre escrita en forma de lira:

Si a una cabeza humana, muy peinada a la moda y muy galana, le añadiera un pintor plumas de gallo y un pescuezo de burro o de caballo; si juntando las piezas desiguales de varios animales por último en el lienzo retratara una mujer de lindo talle y cara con alas de avestruz o de gallina y cola de merluza o de sardina, ¿quién, amigos Pisones, dejara de reírse a borbotones?

\footnotetext{
${ }^{2}$ Esta investigación no habría sido posible sin la espléndida biblioteca digital ECCO (Eighteenth-Century Collections Online), en donde pueden encontrarse todos los libros de zoología aquí analizados.

${ }^{3}$ En el siglo XVIII se traducía la Poética de Horacio como ejercicio de traducción para aprender latín clásico. La versión de Iriarte fue de las más célebres, pero elegí la de Samaniego por tener más resabios dieciochescos.
} 
Pues a este lienzo semejante fuera,

el poema o quimera, cuyas partes sin tino colocadas, no fuesen a una forma conspiradas, cual especie fantástica o locura de quien sueña teniendo calentura. No hay duda que poetas y pintores siempre han sido legítimos señores de fingir y mentir, más que otra gente, lo sé muy bien y todos mutuamente nos pedimos y damos este gran privilegio que gozamos. Mas no por eso se nos da licencia de escribir y pintar sin congruencia, de suerte que se junten como amigos dos animales entre sí enemigos, o se tengan cariño verdadero el tigre y el cordero, las aves y serpientes.

$(\text { Samaniego })^{4}$

El encabezado de esta sección reza "Crítica universal para conocer el mérito de cualquier obra y escribir con perfección, materia y partes del poema". Al poeta se le advierte que no debe abusar de la licencia poética de la inventio. Su creatividad debe basarse en los dictados de la congruencia y la armonía, si ha de aspirar a "escribir con perfección". La claridad y la mesura son los valores más importantes, so pena de hacer el ridículo de no cumplir con ellos. ${ }^{5}$

En esta época, como es bien sabido, se empieza a describir el medievo como la era del oscurantismo, se censuran los excesos del barroco y se busca restaurar un ideal de armonía guiada por la mesura, en la que las formas clásicas sean el paradigma tanto del arte como de la ciencia. Se traza una delimitación tajante entre lo propio y lo impropio, lo decoroso y lo indecoroso, lo normal y lo monstruoso, delimitación que se verá reflejada y difundida más que nunca a través de los medios impresos. Por un lado, se da una revolución en el acceso a la ciencia y la cultura por medio de libros más baratos y de temas más diversos, y por el otro, el espacio digamos democrático de los libros se abre también, paradójicamente, para expresiones heterodoxas que incluyen a

\footnotetext{
${ }^{4}$ Era texto inédito hasta su inclusión en Obras completas. El manuscrito procede de la Fundación Sancho el Sabio (Vitoria), Mss. MAN-871, R. 4558637 ff. Una parte del mismo se recoge en otra copia intitulada "Las artes liberales", Fundación Sancho el Sabio (Vitoria), signatura: MAN871, R. 45585, $10 \mathrm{ff}$.

${ }^{5}$ Ver también Francisco Salas Salgado. 2007. Los clásicos latinos y su traducción en el siglo XVIII: las reflexiones de Juan y Tomás de Iriarte. Madrid: IDEA, p. 60.
} 
la monstruosidad vista ahora a través del filtro racional. Que Iriarte, Samaniego y muchos más emprendieran la tarea de traducir a los clásicos es una muestra del afán racionalista por rechazar la estética que les antecedió al inscribirse en la naturalidad percibida en los clásicos. Sin embargo, lo grotesco está presente en el mismo Horacio, puesto que al nombrarla, se construye en la mente del lector una imagen monstruosa hecha de partes disímbolas que, según el vate, mueve a la risa, pero que igualmente pudiera despertar terror, si ése fuera su objetivo.

El ojo racional de los poetas ilustrados de alguna manera crea una nueva modalidad de monstruo, que apela a la curiosidad, al juicio y a la evaluación. El primero de estos impulsos, la curiosidad, tradicionalmente se había considerado un vicio, a menudo un vicio femenino, pero en esta época pasa a ser más bien una virtud masculina. El juicio y la evaluación, en cambio, se adelantan y se ponen por encima del fenómeno a observar, para de antemano circunscribir la percepción a la esfera racional. La representación gráfica del mundo natural, en particular de la fauna, revela los procesos y determinantes históricas que reflejan, si bien de manera involuntaria, estos valores, así como los principios de abstracción y clasificación que definieron el curso de la zoología hasta nuestros días. La ambición enciclopedista se nutre de los adelantos técnicos y de los viajes de exploración, al tiempo que encuentra en la imprenta un medio ideal y más democrático para dar a conocer sus hallazgos y construir su autoridad. El discurso científico se yergue en dogma al proclamar la expulsión definitiva del error. Sin embargo, insisto, es justamente en los momentos de transición o reacomodo entre diferentes tipos de saber cuando se presentan áreas turbias en las que se revela la tendencia ideológica que impregna todo discurso, aun cuando este discurso pretenda ser inmune a la ideología.

Parecería un verismo afirmar que un bestiario medieval tiene menos en común con un tratado de zoología de nuestro tiempo, que una historia natural elaborada en la Ilustración; sin embargo, todavía en el siglo XVIII se encuentran ejemplos sugerentes de la manera en que se generó el conocimiento de hoy, sin haber dejado atrás por completo las ideas "no científicas" del pasado. Las clasificaciones de Linneo en su Systema Naturae (1735) o George Louis Le Clerc, conde de Buffon, en su monumental Histoire naturelle (1749-88) no son una ruptura tan tajante con los libros equivalentes enmarcados en un paradigma cristiano. Por ejemplo, la Historia Animalium (1551-1558) de Conrad Gesner fue por un lado un esfuerzo de clasificación muy ambicioso y a gran escala, pero todavía se regía por principios no racionales pues buscaba presentar a los animales en el orden en que fueron creados por Dios. Esto nos revela que los códigos de la representación científica se vuelven posibles gracias a la tradición de las representaciones religiosas. El afán de reunir a todas las criaturas bajo un mismo título puede describirse como enciclopedista o bien como una emulación del arca de Noé. La implicación incuestionada en ambos casos es la superioridad del hombre por encima de todas las criaturas contenidas en su libro, y, en el caso de los libros de zoología del siglo XVIII, la superioridad de quien hace el libro por encima de todas las naciones en donde habitan esos animales. 
La representación de los animales ha ido siempre acompañada de una carga semántica en áreas que no son propiamente científicas; tiene un significado cultural, social o político que puede funcionar metafórica o alegóricamente como una representación de la sociedad en donde se gesta (Palmeri: 3). Las categorías binarias que se dan por sentadas tales como grande o pequeño, nacional o extranjero, natural o exótico, puro o híbrido, normal o anormal, se generan y expresan cándidamente en el siglo XVIII, sin producir ningún tipo de culpa o cuestionamiento; a veces llegan incluso a definir lo que podría llamarse una política racial en la que la otredad animal se funde con la otredad humana. Estas categorías revelan lo que una sociedad valora y quiere para sí, es decir, con lo que se identifica, y por otra parte lo que condena y rechaza; esto último lo atribuye invariablemente a la otredad.

La clasificación de las criaturas es un claro ejemplo del proyecto ilustrado descrito por Foucault como la acumulación de un conocimiento que buscaba ser exhaustivo acerca del mundo, presentado en esquemas tabulares. Los nombres científicos en latín, por ejemplo, son el vehículo de apropiación del mundo natural inventariado, así como la herramienta de separación entre doxa y pseudodoxa, entre el conocimiento elitista dominante y la desprestigiada sabiduría popular. También tiene el efecto de subrayar las líneas divisorias entre las especies, al tiempo que éstas se convierten en el objeto subordinado de la descripción en lenguaje humano, misma que los aleja discursiva y éticamente de la humanidad (Palmeri: 4).

Los libros de fábulas, que pintan animales parlantes, son una manera de replantear o incluso desfasar el discurso antropocéntrico. También están las historias de santos, ermitaños o exploradores que prefieren renunciar a la compañía de las personas a favor de la de los animales (san Antonio, san Francisco y Gulliver son ejemplos bien conocidos). En el contexto de los proyectos enciclopedistas tenemos por un lado la enorme popularidad de que gozaron los libros de fábulas - una apropiación más del mundo clásico - y por el otro la proliferación de los libros de zoología ilustrados. Confrontar ambos tipos de saber nos permite presenciar el choque de dos tipos de conocimiento que contendían en la batalla entre antiguos y modernos, además de atestiguar lo que desde la perspectiva actual son los errores de la ciencia dieciochesca, mismos que resultan por demás fascinantes.

Circulaba en Inglaterra un libro de fábulas de Esopo y otros fabulistas dividido en tres partes: fábulas antiguas, fábulas modernas y fábulas recién inventadas (newly invented). Una de éstas es la fábula intitulada The Monster in the Sun, que trata de un astrónomo que está observando el sol con un telescopio para hacer un dibujo de las manchas solares. En eso, apareció en la superficie del sol un monstruo enorme. Y cito: "A Monster of enormous size, and horrible form; it had an immense pair of wings, a great number of legs, and a long and vast proboscis; and that it was alive, was very apparent, from its quick and violent motions..." (Dodsley: 159).

El astrónomo estaba viendo al monstruo con sus propios ojos, $\mathrm{y}$, acostumbrado a comprobar todo por el método experimental, no podía dudar de la veracidad de sus propios sentidos. Según sus cálculos, el monstruo era siete u ocho veces más grande 
que la luna, y tenía, como la salamandra, una extraordinaria resistencia a las altas temperaturas. Existía la posibilidad de que el monstruo volara hacia la Tierra y causara su destrucción total. El astrónomo estaba preparando su teoría para publicarla, cuando un colega suyo examina el microscopio y descubre una mosca atrapada entre los cristales. La moraleja concluye que, con mucha frecuencia, las faltas o cosas extraordinarias que percibimos están no en el objeto, sino en la mente del observador (180).

La fábula no sólo revela un sano escepticismo hacia la ciencia, sino que también expresa de manera implícita que el factor mental, léase ideológico y sociocultural, siempre expresará una verdad distorsionada por los intereses del observador. En ese sentido, veremos varios ejemplos de actitudes científicas, religiosas, literarias y sociales hacia los monstruos en el siglo XVIII, con objeto de resaltar el papel fundamental que jugó la imprenta para modelar actitudes que perduran incluso hasta nuestros días. La cercanía entre el discurso de la monstruosidad y los discursos científicos, literarios y religiosos es tal, que, como en la fábula del monstruo solar, tienden a borrarse los límites entre la realidad y la fantasía.

En gran medida, la confusión se originó con la aparición de la Micrographia de Robert Hooke, publicada por primera vez en 1665 con el título de Micrographia, or some Physiological Descriptions of Minute Bodies made by Magnifying Glasses. Fue la primera publicación importante de la Royal Society y se considera el primer bestseller científico, pues capturó la imaginación del público de un modo muy novedoso. No se puede negar que el contenido del libro tiene trascendencia hasta el presente. Sin embargo, es la tecnología y el diseño del libro y el manejo de las ilustraciones lo que volvió su impacto aún mayor. El ejemplo clásico es la pulga, pero hay varias imágenes igualmente amenazantes, como la de la hormiga, la araña y el piojo, en impresiones de gran formato a veces desplegables que ocupaban el espacio de un folio entero. En una época en la que no existía la fotografía, mucho menos la fotografía microscópica, los grabados, llenos de pequeñas letras y números que desglosan su sorprendente anatomía, tuvieron un impacto profundo. La gente común y corriente, no los héroes de romances ni de las gestas épicas, la gente cotidiana, de repente se encontró rodeada de monstruos que desde siempre habían ocupado el espacio cotidiano; los monstruos estaban por doquier, invadiendo los objetos, la comida, el cuerpo mismo. Los monstruos estaban ahí, si tan sólo se tenía el instrumento adecuado para verlos. En todo caso, el libro mismo servía para prevenir al público, para ponerlo en estado de alerta hacia los posibles peligros invisibles. Es como si el libro mismo fuera un zoológico virtual que albergaba monstruos, pero también revelaba el aspecto monstruoso de la técnica de impresión en sí misma. Así, por ejemplo, Hooke incluye también la extraordinaria representación de un punto de tinta magnificado bajo el microscopio, una esfera irregular y peluda que revela al monstruo que esconde la tinta. ${ }^{6}$

\footnotetext{
${ }^{6}$ Siglos después, en 1848, Hans Christian Andersen escribiría el cuento "La gota de agua", que trata acerca de un mundo microscópico poblado por diminutos habitantes, con ciudades y sus guerras, y donde aún se puede ver el asombro que despertaban estas imágenes.
} 
Ahora bien, el microscopio reveló el mundo de las criaturas diminutas, pero los libros ilustrados también permitieron un acercamiento a mundos geográficamente distantes, y las criaturas que los habitaban, en todo su esplendor y su exotismo, o al menos tanto como la técnica del grabado fuera capaz de captar, complementado, por supuesto, por la explicación científica. Así, por ejemplo, tenemos otro libro fascinante: $A$ General History of Quadrupeds, de Ralph Beilby, ilustrado por T. Bewick y publicado en 1790. Todo el libro está construido en torno a las imágenes, que son más de un centenar. Aquí lo que quiero destacar es, en primer lugar, que se traza una división entre los animales "comunes" (common) y los raros, los exóticos, los diferentes. Mi primer ejemplo es el del carnero común, el common ram, totalmente domesticado, resultado de cruzas totalmente controladas por el hombre: "Climate, food, and above all, the unwearied arts of cultivation, contribute to render this animal, in a peculiar manner, the creature of man" (Beilby: 36). Aquí es irresistible hacer notar la actitud triunfal del ganadero criador y creador de animales a su gusto a través de la manipulación genética permitida por las cruzas controladas. Es casi como un dios. ${ }^{7}$

En contraste con el carnero común, tenemos al dunky o carnero enano, que se destaca por "the singular and grotesque formation of its features" (46). Para un observador amateur, los rasgos particulares podrían pasar inadvertidos en la imagen, pero el texto se encarga de etiquetarlos como grotescos al explicar puntualmente cómo se distingue de un carnero "normal". La lana le crece alrededor de la cabeza formando una especie de capucha o gorguera, que envuelve las orejas erectas; tiene la quijada extrañamente prominente a tal grado, que se le asoman los dientes delanteros; tiene la nariz muy corta, por debajo de la frente abultada. Todos estos rasgos "give it the appearance of deformity, and make a striking contrast to most animals of the Sheep kind" (46). Luego se aclara que este borrego es extranjero, lo cual refuerza su rareza generalizada; aunque no se especifica de dónde viene, la implicación es que los carneros nacionales, es decir ingleses, son normales, y las desviaciones de esta norma son deformaciones grotescas.

Después tenemos un animal aún más espectacular: el borrego de muchos cuernos o many-horned sheep. Aunque en la imagen parece tener tres cuernos, dos "normales" a los lados y uno en medio, la explicación dice que llegan a tener a veces cuatro, a veces ocho cuernos, y que vienen de Islandia y Moscovia. En ese mismo apartado, sin imagen, se menciona la oveja de cola ancha, común en Persia, Barbaria, Siria y Egipto. Son ovejas con una cola que mide un pie de ancho, tan estorbosa, que los pastores se ven obligados a ponerles unas tabletas con rueditas a las colas para que no se les atoren. El texto añade que la carne de estas colas se considera una delicadeza culinaria. También se menciona la oveja del Tibet que produce una lana de largo y finura extraordinarios, con la que se hace el célebre chal hindú que se vendía ya desde entonces en Inglaterra al precio exorbitante de cincuenta libras (49).

${ }^{7}$ Los animales que son el fruto de la manipulación genética constituyen un éxito científico, como se vivió en 1996 con la célebre oveja Dolly, creada a partir de la ubre de otra oveja, las implicaciones en la actualidad, sin embargo, son muy distintas y ocuparse de ellas rebasa los propósitos de este estudio. 
Además de animales domésticos, el libro incluye una gran variedad de animales salvajes, vistos y dibujados según las descripciones de los exploradores que viajaron, por ejemplo, a la sabana africana. La representación de la cebra, por ejemplo, concuerda con la idea que se tiene en nuestro tiempo de ese animal en cuanto a sus proporciones y a las rayas que lo caracterizan. Está retratada de perfil con el objeto de hacer resaltar más su figura. En ésta como en todas las imágenes del libro, la imagen está arriba y el texto abajo. La premisa es que el texto se ocupará de precisar aquellos rasgos que no transmita la imagen. Aquí es curioso observar que el comentario, con afán científico, insiste en la belleza del animal. La cebra, dice

[...] is the most beautiful, as well as the wildest, most timid, and untameable animal in nature. Being larger than the Ass, it rather resembles the Mule in shape: Its head is large; its ears Larger than those of the Horse; its legs beautifully small, and well placed; and its body well formed, round, and fleshy: But the beauty of its shape is greatly heightened by the glossy smoothness of its skin, and the Amazing regularity and elegance of its colours... in a stile so beautiful and ornamental, that it would at first sight seem rather the effect of art than the genuine production of nature... it only requires the efforts of an industrious and skilful nation, to be added to the number of our useful dependants. They have continued to be wild, because they are natives of a country where the wretched inhabitants have no other idea of advantage from the animal creation than as they are good for food... (16-17).

Conocemos lo nuevo por medio de comparaciones con lo conocido. Así, el autor recurre al asno, la mula y el caballo para explicar qué es la cebra. Sus rayas, en cambio, resultan inexplicables y por lo tanto sugiere que parecen ser obra de la mano del hombre y no naturales. Su carácter ornamental establece una analogía indirecta con la vestimenta humana que en aquella época conoció excesos singulares. Además, el autor no puede evitar el comentario xenófobo de culpar a los míseros habitantes del país de la cebra de no domesticarla, al tiempo que asegura que en manos de una nación industriosa y diestra - como la inglesa - se lograría domesticar. La ignorancia y la condescendencia del comentario saltan a la luz desde nuestra perspectiva, pero todo el texto busca interpretarse como verdad científica.

Encontramos un antropomorfismo similar en la representación del león, cuyas características bien pudieran ser las de un monarca o las de un monstruo legendario, pues, además de distinguirse por su melena, su tamaño y su fuerza, se le representa con el ceño fruncido y se dice que "reina como amo único" del reino animal.

"The form of the Lion is strikingly bold and majestic: His large and shaggy mane, which he can erect at pleasure, surrounding his awful front; his huge eye-brows; his round and fiery eye-balls, which, upon the least irritation, seem to glow with peculiar lustre; together with the formidable appearance of his teeth, exhibit a picture of terrific grandeur, which no words can describe" (166).

En este ejemplo es innegable que se han traslapado los discursos, pues el catálogo de las partes del león está impregnado de un deleite poético derivado directamente de 
las descripciones de los monstruos. Incluso pudiera sugerirse que, en el contexto inglés, hay una alusión al régimen monárquico. ¿Nos habla esto de la monstruosidad del monarca, o bien de que la monarquía es una forma de gobierno tan natural que se repite en el reino animal? Ambas interpretaciones quedan insinuadas. Más sorprendente aún para nosotros es el hecho de que, en última instancia, se considera al león como una alimaña indeseable que se busca exterminar: "Happily, indeed, the species is not numerous, and is said to be greatly diminished; for, if we may credit the testimony of those who have traversed these vast deserts, the number of Lions is not nearly so great as formerly" (164-65). ¿Se aplica también esto a los reyes?

El tigre en cambio desata una sarta de adjetivos alusivos a su despiadada ferocidad, que lo vuelve monstruoso en su crueldad.

The Tiger is the most rapacious and destructive of all carnivorous animals. Fierce without provocation, and cruel without necessity, its thirst for blood is insatiable: Though glutted with slaughter, it continues its carnage, nor ever gives up so long as a single object remains in its sight. Flocks and herds fall indiscriminate victims to its fury: It fears neither the sight nor the opposition of man, whom it frequently makes its prey; and it is even said to prefer human flesh to that of any other animal (171).

Si la nobleza del león se subraya en repetidas ocasiones, lo mismo ocurre con la crueldad del tigre, que se perfila entonces como un monstruo maléfico devorador de hombres. Sus matanzas son sangrientas y crueles, y parece regodearse en la sangre y la destrucción. A diferencia del león, que se puede domesticar un poco, el tigre posee una ferocidad que jamás se aplaca. Se dice que ataca toda clase de animales, incluyendo al león, por lo cual se perfila no como un rey sino como un traidor de reyes, un hermano segundo, celoso del primogénito (172). La imagen, escribe el autor, es muy fiel a la realidad, pues en 1787 se exhibió un tigre en Newcastle, donde el público pudo apreciar la terrible belleza de sus rayas (173). Para subrayar su parentesco aristocrático con el león, la especie se denominó tigre real (royal tiger) (174).

Sólo cuatro años después, William Blake publicaría en sus célebres Songs of Experience (1794) uno de los poemas más citados en lengua inglesa, "The Tyger", que mantiene la nota de asombro ante el tigre como obra del Creador. Se ha comentado que la imagen que acompaña al poema no retrata a un tigre feroz. Sin embargo, su "fearful symmetry" ¿no será acaso evocadora de los libros de zoología de la época, una evocación que rectifica y rescata al tigre de su descripción semiempírica? "The Tyger" exalta el horror y la belleza de la creación por encima de la razón. El tigre de Blake se forjó con materia estelar en la fragua divina; el fuego de sus ojos procede de los abismos infernales; sólo un dios hercúleo pudo torcer los nervios que ciñen su musculatura. Es la contraparte del cordero de las Songs of Innocence; éste representa el perdón divino y aquél la ira de Dios (Damon: 277).

De los ojos flamígeros del león de Beilby al fuego en los ojos del tigre de Blake aparentemente no hay tanta distancia, como sí la hay a todas luces entre los borregos de Beilby y el cordero de Blake. Al tiempo que busca el anclaje racionalista y desmitificador, 
el primero construye su credibilidad con anécdotas y testimonios acerca de las características y costumbres del león, sin preocuparse por el hecho de que sus adjetivos estén tomados del glosario poético. El segundo, en cambio, construye métricamente un tono profético destinado a reconstruir el aura de asombro que la ciencia procuraba desterrar. Los animales de Beilby, monstruosos en su exotismo, son objetos de exhibición en el museo ilustrado y el gabinete de curiosidades; los animales de Blake, en el espacio privilegiado de la idea poética, rescatan la maravilla más allá de lo monstruoso y apuntan a una realidad espiritual o cósmica, fuera del alcance del microscopio, el telescopio o los ojos de cualquier explorador. No es de extrañarse que hubiera respuestas muy negativas a su obra. Charles Cestre vislumbraba en su poesía indicios de locura: "Blake a perdu sa sérénité. A partir de ce moment, son esprit se trouble. Il ne conserve assez de lucidité pour concevoir un plan de poème intelligible" (apud. Damon: 276). Sin embargo, en su crítica implacable del paradigma racional, Blake coincidiría sin duda con Goya al afirmar que quienes padecen esta demencia son quienes duermen el sueño de la razón, y son ellos quienes producen monstruos.

\section{Obras citadas}

BEILBY, Ralph. 1790. A General History of Quadrupeds: The figures engraved on wood by T. Bewick. Newcastle upon Tyne: ECCO. Gale Document Number: CW3307220919. 25 de julio de 2013.

Benedict, Barbara M. 2001. Curiosity: A Cultural History of Early Modern Inquiry. Chicago: University of Chicago Press.

Blake, William. 1977. The Portable Blake. Ed. Alfred KazIN. Nueva York: Penguin.

DAmon, S. Foster. 1958. William Blake. His Philosophy and Symbols. Gloucester, Mass.: Peter Smith.

DodSLEY, Robert. 1761. Select Fables of Esop and other fabulists. Londres: A new Edition. Gale Document Number: CW113866486. 25 de julio de 2013.

FoucAult, Michel. 1985. Las palabras y las cosas. Trad. Elsa Frost. México: Siglo XXI.

Granata, Silvia. 2011. Take Every Creature In, of Every Kind: Continuity and Change in Eighteenth-Century Representations of Animals. Nueva York: Peter Lang Publishing. 25 de julio de 2013. <http://books.google.com.mx/books/ about/Take_Every_Creature_In_of_Every_Kind $>$. html?id=zelKYgEACAAJ\&redir_esc $=\mathrm{y}$.

Holmes, Richard. 2008. The Age of Wonder. How the Romantic Generation Discovered the Beauty and Terror of Science. Nueva York: Pantheon.

HoOKe, Robert. 1745. Micrographia restaurata: or, the copper-plates of Dr. Hooke's wonderful discoveries by the microscope, reprinted and fully explained: whereby the most valuable particulars in that celebrated author's Micro- 
graphia are brought together in a narrow compass; and Intermixed, occasionally, with many Entertaining and Instructive Discoveries and Observations in Natural History. Londres: John Bowles. En ECCO, Gale Document Number: CW108677547. 25 de julio de 2013.

Horacio. Arte poética. 1777. Trad. Tomás De IRIARTE. En Biblioteca de Traductores. Madrid: Real de la Gazeta. 25 de julio de 2013. <www.traduccionliteraria.org/biblib/H/H101.htm>.

Palmeri, Frank. 2006. Humans and Other Animals in Eighteenth-Century British Culture. Southport: Ashgate Pub. Co.

SALAS, Francisco. 2007. Los clásicos latinos y su traducción en el siglo XVIII: las reflexiones de Juan y Tomás de Iriarte. Madrid: IDEA.

Samaniego, Félix María de. 2003 Versión parafrástica del "Arte poética" de Horacio. Ed. Emilio PALACIOS FernándeZ. Alicante: Biblioteca Virtual Miguel de Cervantes. 25 de julio de 2013. <http://www.cervantesvirtual.com/ servlet/SirveObras/02416163101818164754491/p0000001.htm\#I_2_>. 25 de julio de 2013. 